\title{
Correction to: Comparison of Patient-Reported and Caregiver-Reported Swallowing-Related Quality of Life in Parkinson's Disease
}

\author{
Allie S. Zimmerman ${ }^{1} \cdot$ Samantha Shune ${ }^{2} \cdot$ Kimberly G. Smith $^{1} \cdot$ Julie M. Estis ${ }^{1} \cdot$ Kendrea L. Garand $^{1}$ (i)
}

Published online: 21 May 2021

○) Springer Science+Business Media, LLC, part of Springer Nature 2021

\section{Correction to: Dysphagia \\ https://doi.org/10.1007/s00455-021-10301-8}

The original version of the article unfortunately contained reference errors. That is author order is incorrect for references 25 and 27 and wrong journal cited for reference 27.

The correct citations are provided below:

25. Shune S, Namasivayam-MacDonald A. Swallowing impairments increase emotional burden in spousal caregivers of older adults. J Appl Gerntol. 2020;39(2):172-80. https://doi.org/10.1177/0733464818821787.
27. Shune S, Namasivayam-MacDonald A. Dysphagiarelated caregiver burden: moving beyond the physiological impairment. Persp ASHA Spec Interests Groups (SIG 13 Swallowing and Swallowing Disorders). 2020;5(5):1282-9. https://doi.org/10.1044/2020_PERSP-20-00067.

Publisher's Note Springer Nature remains neutral with regard to jurisdictional claims in published maps and institutional affiliations.

The original article can be found online at https://doi.org/10.1007/ s00455-021-10301-8.

Kendrea L. Garand

garand@southalabama.edu

1 Department of Speech Pathology and Audiology, University of South Alabama, HAHN 1119, 5721 USA Drive North, Mobile, AL 36688, USA

2 College of Education, University of Oregon, 1215 University of Oregon, Eugene, OR, USA 